\title{
The Effect of Children's Negative Automatic Thoughts on Their Problematic Smartphone Use: The Moderating Effect of Weekend Family Rituals
}

\author{
Daeun Kim ${ }^{1}$, Kyung Eun Jahng ${ }^{2}$ \\ Researcher, Seoul Welfare Foundation, Seoul, South Korea ${ }^{1}$ \\ Associate Professor, Department of Child \& Family Studies, Kyung Hee University, Seoul, South Korea ${ }^{2}$ \\ 아동의 부정적 자동적 사고가 스마트폰 의존도에 미치는 영향: \\ 주말가족활동 의례의 조절효과 \\ 김다은 ${ }^{1}$ 장경은 ${ }^{2}$ \\ 서울시복지재단 위촉연구원, 경희대학교 아동가족학과 부교수 ${ }^{2}$
}

\begin{abstract}
Objectives: The prevalence of smartphone use among children raises concerns about the potential for problematic smartphone use. According to previous findings, it was reported that psychological factors affect children's problematic smartphone use. However, cognitive factors affecting children's problematic smartphone use have not been investigated enough. To find out how to mitigate and prevent their problematic smartphone use, the present study explores whether children's negative automatic thoughts affect their problematic smartphone use. It also seeks to investigate the moderation effect of weekend family rituals on the relationship between children's negative automatic thoughts and problematic smartphone use.

Methods: The study participants included 274 fifth and sixth graders attending elementary schools in Seoul and Incheon, South Korea. Statistical analysis for the present study was conducted using SPSS 22.0 and PROCESS macro version 3.2.

Results: The study found that children's negative automatic thoughts are positively related to problematic smartphone use. In addition, children's negative automatic thoughts are adversely related to weekend rituals, and weekends ritual are also negatively associated with children's problematic smartphone use. Children's negative automatic thoughts have an effect on their problematic smartphone use. It also found that weekend family rituals moderated the association between children's negative automatic thoughts and their problematic smartphone use. That is, children who automatically perceive themselves negatively tend to be dependent on smartphones.

Conclusion: Based on the results, this study suggests that it is necessary not only to design intervention programs for preventing children's problematic smartphone use but also to support work and life balance so that families can create and maintain their weekend family rituals.
\end{abstract}

Keywords: negative automatic thoughts, problematic smartphone use, weekend family rituals

Corresponding Author: Kyung Eun Jahng, Department of Child \& Family Studies, Kyung Hee University, 26, Kyunghee-daero, Dongdaemun-gu, Seoul, Korea

E-mail: jahng78@gmail.com
(C)The Korean Association of Child Studies

This is an Open Access article distributed under the terms of the Creative Commons Attribution Non-Commercial License (http:// creativecommons.org/licenses/by-nc/4.0) which permits unrestricted noncommercial use, distribution, and reproduction in any medium, provided the original work is properly cited. 


\section{Introduction}

국내의 스마트폰 보유율은 지난 10 년간 꾸준히 증가해왔다. 2018 한국 미디어 패널 조사(Korea Media Panel Survey [KMPS], 2018)에 따르면 2011년 21.6\%였던 스마트폰 보유율이 2018년 에는 $87.2 \%$ 까지 증가하였다. 또한, 초등학교 저학년(1-3학년) 의 스마트폰 보유율은 2011년 1.2\%에서 2018년 37.8\%로, 고 학년(4-6학년)의 보유율은 2011년 4.4\%에서 2018년 81.2\%로 급증하였다(Korean Information Society Development Institute [KISDI], 2018). 아동의 높은 스마트폰 보유율은 아동의 스마트 폰 과의존을 발생시킬 수도 있다는 우려로 이어지고 있다. 그 러나 2018 스마트폰 과의존 실태조사에 따르면 아동의 스마트 폰 과의존 위험군은 전체 조사 대상자 중 $2.0 \%$ 에 불과하며 잠 재적 위험군은 $18.7 \%$ 에 불과하다(Ministry of Science and ICT [MSICT] \& National Information Society Agency [NIA], 2019). 이는 아동의 높은 스마트폰 보유율에 비하면 아동의 스마트폰 과의존 수준은 낮은 수준이라고 말할 수 있다. 이 실태조사 결 과를 통해서 추측해볼 수 있는 것은 스마트폰을 사용하는 것 자체만이 아동의 스마트폰 의존을 유발한다기보다는 그 외의 다른 요인이 스마트폰 의존에 영향을 미칠 수 있다는 점이다.

선행연구에서 밝혀진 아동의 스마트폰 의존에 영향을 미치 는 변인들을 살펴보면 다음과 같다. 우선, 사회 인구학적 변인 으로는 성별과 연령이 있다. 인터넷 의존에서 성별에 따른 차 이에 관한 연구 결과에 따르면, 인터넷을 사용하는 목적과 동 기는 성별에 따라 차이가 있다. 여성의 경우 채팅이나 커뮤니 티 사이트에서 익명으로 타인과 친밀한 관계를 형성하거나, 친구들과 소통하는 목적을 갖고 인터넷을 사용하는 경향이 있 다(Song et al., 2009). 반면, 남성의 경우 오락적 목적을 위해 인 터넷을 사용하는 경향이 높고 특히 자신의 힘을 과시하거나 의지에 따라 상황을 통제할 수 있는 인터넷 게임에 더 많은 시 간을 보내는 경향이 있다(Young, 1998). 이러한 성별에 따른 차이는 스마트폰 사용에서도 비슷한 양상을 보인다. 남성이 주로 사용하는 앱은 '게임' 관련 앱이며 여성이 주로 사용하는 앱은 친구 또는 타인과 소통할 수 있는 '메신저' 앱으로 나타났 다(KISDI, 2017). 스마트폰을 의존적으로 사용하는 동기에서 도 성별에 의한 차이가 있다. 여성의 경우 심리적 상태와 같은 내적 동기의 영향을 받지만, 남성의 경우 보상이나 명성과 같 은 외적 동기의 영향을 받는 경향이 있다(Chen et al., 2017). 같 은 맥락으로 여아는 우울이 높을수록, 남아는 공격성이 높을 수록 스마트폰을 과도하게 사용하는 경향을(E. Park \& Park, 2014) 보인다.
한편, 아동의 연령도 스마트폰 의존과 관련 있는 변인으로 밝혀졌다. 패널데이터를 사용하여 초등학교 4학년 때부터 2 년 간격으로 휴대전화 의존도의 변화를 살펴본 종단연구(G.H. Hwang, Cho, \& Hyun, 2016)와 초등학교 1학년부터 중학교 1 학년까지 6년 동안 아동을 추적하여 스마트폰 의존도의 변 화 양상을 살펴본 종단연구(H. Lee \& Yang, 2018)에서 학년이 증가함에 따라 휴대전화나 스마트폰 의존도가 증가한다는 것 이 밝혀졌다.

반면, 청소년이 지각한 가정의 주관적 경제 수준은 스마트 폰 의존도에 영향을 미치지 않았다. Jeong과 Lee (2020)의 연구 에서는 초등학교 4학년의 주관적 경제 수준이 낮을수록 스마 트폰 의존도에 유의미한 영향을 미쳤으나, 중학교 1학년의 주 관적 경제 수준은 스마트폰 의존도에 영향을 미치지 않는 것으 로 나타났다. E. J. Lee (2019)의 연구에서도 중학생이 인식한 주 관적 경제 수준은 스마트폰 의존도와 관련이 없는 것으로 밝혀 졌다. 가족 구조 역시 스마트폰 의존도와 관련이 없다고 보고 된 바 있다. Choi (2019)는 한부모 가정의 유아와 일반가정 유 아 간의 스마트폰 의존도 차이는 없는 것으로 보고하였다. 어 머니의 교육 수준과 아동의 스마트폰 의존도 사이에 유의미한 상관을 보이지 않았다는 연구(Shin \& Jeong, 2018)도 있다. 따 라서 본 연구에서는 선행연구에서 스마트폰 의존도에 영향을 미치는 것으로 일관적으로 보고된 바 있는 변인인 아동의 성 별, 연령, 스마트폰 사용시간을 통제변수로 사용하였다.

다음으로 스마트폰 의존에 영향을 미치는 아동의 개인적 특성으로는 아동의 우울(Elhai et al., 2018; S. Hwang \& Lee, 2018; Jin \& Shin, 2016), 외로움(Byun \& Kweon, 2014; Yuh, 2016), 자아존중감(Bianchi \& Phillips, 2005; Jang, Kim, Choi, \& Lee, 2013; D. Kim \& Jahng, 2019; H. N. Lee \& Kim, 2018) 등이 연구됐다. 이와 같은 개인의 심리정서적 요인은 아동 의 사고(thought) 과정에 영향을 미치며, 아동의 사고는 아동 의 행동과 그 행동의 동기에 영향을 미친다고 보고된 바 있다 (Shadrikov \& Kurginyan, 2017). 즉, 아동은 내면의 사고 과정을 거쳐 자신의 행동을 선택한다. 지금까지 아동의 스마트폰 의 존에 영향을 미치는 요인들 중에서 심리정서적 요인에 초점 을 맞춘 연구(Byun \& Kweon, 2014; Jin \& Shin, 2016; J. Park \& Cho, 2020)가 상당수 진행된 반면, 인지적 사고 과정이 아동의 스마트폰 의존에 미치는 영향에 관한 연구는 상대적으로 부족 하다. 스마트폰 의존도를 낮추기 위해서 다각도로 개입 방법 을 모색하기 위해서는 관련 요인들에 관한 폭넓은 조사가 요 구된다. 따라서 본 연구에서는 아동이 스마트폰을 의존적으로 사용하는 행동에 영향을 미칠 수 있는 인지 사고 과정을 좀 더 
자세히 살펴보고자 한다.

인지치료의 선구자인 Beck (1976)은 우울증 환자들을 치 료하며 이들이 왜곡된 신념에 의한 비합리적인 사고를 한다 는 공통점을 발견하였다. 여기서 말하는 왜곡된 신념은 개인 이 성장하면서 경험한 사건들을 바탕으로 형성되는 무의식 적 인지 구조인 인지 도식(schema)을 토대로 구성된다(Beck \& Alford, 2009). 사람들은 각자 어떤 환경적 자극이나 정보 를 접했을 때 자신의 신념에 따라 어떠한 생각을 자연스럽 게 떠올리는데, 부정적인 사건들을 반복적으로 경험한 개인 은 자기 자신, 세상 그리고 미래에 대해서 왜곡적으로 해석하 게 하는 인지 도식을 형성해 왔을 가능성이 크고 이러한 인지 도식에서 발현된 자동적 사고를 부정적 자동적 사고(negative automatic thoughts)라고 한다. 이때, 부정적 자동적 사고는 아 동이 어린 시절부터 경험한 사건들을 토대로 형성된 인지 도 식에서 발현된 것으로 일시적인 상태가 아닌 체계적 사고 구 조이다(Beck \& Alford, 2009).

부정적 자동적 사고를 하는 개인은 특정 상황을 접했을 때 이를 자동으로 부정적인 방향으로 해석하고 더 적절한 설명 방 법이 있음에도 불구하고 자신의 편향(biased)적 사고에 맞게 상 황을 해석하며 이를 통해 비합리적 의사결정을 내리게 된다 (Beck \& Alford, 2009). 인지적으로 편향된 사고는 자신이 선택 한 행동을 합리화하는 데도 사용된다. Bowler, Bowler와 James (2011)는 중독 경향(addiction proneness)적 행동을 보이는 사람 들의 인지 사고 과정에 관한 선행연구들을 분석하여 그들이 그러한 행동을 선택하거나 반복할 때 관찰되는 합리화 방법 (justification mechanism)의 유형을 소개하였다. 이때, 중독 증상 을 보이는 사람들은 그들의 행동에 대한 합리화 방법으로 "어 쩔 수 없었다."는 식의 반응을 보이는 경향이 있다(Bowler et al., 2011). "어렵고 힘든 지금의 상황을 피하기 위해서", "당장의 즐 거움을 느끼기 위해서", "나의 싫은 점을 잊기 위해서" 또는 "원 래 나는 이렇기 때문이라는 식”으로 합리화하면서 중독된 행 동을 선택하고 반복하는 것이다(Bowler et al., 2011). 즉, 개인이 가진 편향적 사고가 그들로 하여금 비합리적 행위를 선택하게 하고 이것이 반복되면서 중독 행위를 지속하게 된다는 것이다.

여기서 인터넷과 같은 미디어의 과도한 사용의 원인으로 사용자의 왜곡적 인지사고 과정에 주목한 Davis (2001)의 주장 도 함께 살펴볼 필요가 있다. 그는 인지-행동 모델을 통해 인 터넷의 병리적 사용(internet pathological use)의 원인을 사용자 의 부적응적 인지(maladaptive cognitive)라고 설명하고 이를 자 기 자신에 대한 사고(thoughts about the self)와 세상에 대한 사 고(thoughts about the world)로 나누어 설명하였다. '자기 자신
에 대해 부적응적 사고'를 하는 개인은 인터넷이라는 위협적 이지 않은 도구를 통해 타인으로부터 인정을 받고자 한다. 이 들은 반추적(ruminative) 인지 사고의 특성을 보이는데 이로 인 해 인터넷 사용에 대해 반복적으로 떠올리게 되고 이는 인터 넷의 병리적 사용으로 이어진다. '세상에 대해 부적응적 사고' 를 하는 개인은 자신이 인터넷 안에서는 존중받을 수 있으나 인터넷 바깥세상에서는 존중받지 못하고 실패자로 인식된다 고 생각한다. 따라서 인정받기 위한 수단으로서 인터넷을 사 용하게 되며 이것이 인터넷의 병리적 사용으로 이어진다. 이 러한 두 가지의 부적응적 인지 사고는 특정 상황이나 관련된 자극이 있을 때 자동으로 활성화되는 특징을 보이는데(Davis, 2001), 이는 Beck (1976)이 주장한 자동적 사고와 공통적인 특 성을 보인다. 이처럼 왜곡된 사고방식이 비합리적 행동을 선 택하는 데에 영향을 미친다면, 편향적 인지 사고방식인 부정 적 자동적 사고 또한 스마트폰 의존에 영향을 미치는지에 대 해서 살펴보는 것은 아동의 스마트폰 의존을 완화시키기 위한 새로운 방법 마련에 기여할 것이다.

나아가 아동은 아직 자신의 스마트폰을 구매할 수 있는 경 제적 능력이 없고 스마트폰 사용 패턴 또한 가족 구성원들과 의 상호작용 안에서 구성된다. 따라서 아동의 스마트폰 구매 부터 스마트폰의 사용 양상 형성에 이르는 과정은 모두 가족 이라는 맥락 안에서 이해되어야 한다(M. R. Lee \& Park, 2020). 또한, 가족 구성원들과의 상호작용을 통해서 아동은 사회화되 고 자아를 형성해 나간다(Berk, 2005/2008). 아동은 또래 관계 에서 겪는 긴장감이나 학업 수행으로 인해 발생한 스트레스를 건강한 가족과의 관계 속에서 해소하거나 완화시킬 수 있다. 나아가 가족과의 소통을 통해서 아동은 상대방으로부터 적절 한 반응을 얻을 수 있도록 자신의 정서를 표현하거나 갈등을 조절하는 방법에 대해서도 배울 수 있다(Berk, 2005/2008).

아울러 가족은 가족 구성원들로 이루어진 하나의 체계 (system)이다. 여기서 체계란 서로 영향을 주고받는 요소의 복 합체이다(von Bertalanffy, 1968). 가족이라는 체계 내에서 아동 은 개인임과 동시에 가족체계의 한 부분으로서 존재하며 구성 원들과의 상호작용을 통해 끓임없이 영향을 주고받으며 성장 한다. 각 가족체계 내에서 이루어지는 의미 있는 상호작용과 활동을 가족의례(family ritual)라고 하는데, 여기서 의례란 정 형화된 특정한 역할과 의미를 포함한 사회적 상호작용(Fiese $\&$ Kline, 1993)을 말하며, 가족의례란 가족의 가치를 가족 구 성원 사이에서 공유하고 가족 정체성을 증대시키며 가족생활 을 촉진하도록 하는 반복된 행동을(Fiese et al., 2002) 말한다.

가족의례를 결정하고 진행하는 과정에서 구성원들은 가족 
의례 참여자로서 서로의 의견에 대한 피드백을 주고받으며 자 신들의 체계에 적절한 가족의례를 만들어나간다. 또한, 가족 의례는 비교적 규칙적으로 실행되기 때문에 예상 가능하다 는 점에서 가족 구성원들에게 안정감을 줄 수 있다(Fiese et al., 2002). 가족의례를 계획하고 실행해가는 과정은 가족 구성원 들이 서로에 대한 신뢰감을 공유할 수 있고 각자의 역할을 분 명하게 한다. 따라서 가족의례는 가족체계 내에서 발생한 사 건으로 인한 스트레스가 개인에게 미치는 부정적인 영향력을 완화시키는 역할이나 보호적 요인으로 작용 할 수 있다(Kiser, 2007). 가족의례 관련 국내 연구는 가족의례의 유형을 구분하 지 않고 가족의례에 대한 가족 구성원들의 인식(Chung, Son, $\&$ Yoon, 2015)이나 가족의례가 실행되는 정도에 따른 부모자녀 관계에 주목하였다. 가족의례의 유형을 구분하여 살펴 본 Yoo, Kim, Lim과 Choi (2011)의 연구는 가족들의 식사의례 가 아동의 사회성 발달에 미치는 영향을 살펴보았다. 또한 가 족의례는 천식, 암, 비만과 같은 질병을 않는 환자가 있는 가 족(Buchbinder, Longhofer, \& McCue, 2009; Markson \& Fiese, 2000)이나 내재적.외재적 문제행동을 보이는 아동이 있는 가 족(Malaquias, Crespo, \& Francisco, 2015; Y. Yoon, Newkirk, \& Perry-Jenkins, 2015) 내에서 발생하는 갈등이나 스트레스에 대 해 영향력 있는 보호요인으로 밝혀진 바 있다. 이처럼 가족의 례는 부모-자녀 관계나 아동의 발달에 영향을 미치는 유의미 한 변인으로 밝혀졌으나, 아동의 스마트폰 의존에 미치는 영 향에 관해서 연구된 바가 없다.

가족의례의 종류는 다양한데 대표적으로 저녁 식사 의례 (dinnertime ritual), 주말가족활동 의례(weekend ritual), 휴가 의례(vacation ritual), 가족 행사 의례 (annual ritual), 가족 모임 의례(special ritual), 종교 의례(religious ritual)가 있다(Fiese \& Kline, 1993). 본 연구에서는 국내 가족체계의 특성들, 즉, 맞벌 이 부부의 비율이 높고, 이들의 평일 노동 시간이 비교적 긴 점 과 아동들 대부분이 평일 방과 후에 학원 또는 방과 후 교실과 같은 가정 외의 공간에서 시간을 보낸다는 연구결과(Ministry of Gender Equality and Family, 2015)를 고려하여 다양한 유형 의 가족의례 중에서 가족들이 다함께 시간을 보낼 가능성이 높은 주말가족활동 의례를 중심으로 연구를 진행하였다. 주말 가족활동 의례란 주말마다 수행되는 규칙성, 가족 구성원들의 정형화된 역할, 가족 내 유대감 공유의 특성을 띤 가족 단위의 활동을 말한다(Fiese \& Kline, 1993). 물론 아동의 부정적 자동 적 사고가 스마트폰 의존에 미치는 영향에 대한 조절변인으로 서 가족의례 외에도 다른 가족 관련 변인들을 고려해 볼 수 있 겠으나, 가족의례라는 활동은 다른 가족 변인들(예: 가족관계)
보다도 가족 구성원들 간의 합의된 행동이며 외부적 개입에 의한 수정과 변화가 훨씬 용이할 수 있다.

아동의 부정적 자동적 사고 수준이 높은 경우, 그들의 편향 적 사고가 비합리적 행위 가능성을 높이고 이러한 일이 반복 되면서 스마트폰에 의존하는 행위를 지속할 수 있다. 부정적 자동적 사고로 인하여 현실을 부정적으로 왜곡하여 해석하는 인지적 오류를 범할 수 있기 때문에 이러한 인지왜곡으로 인 하여 합리적 행위를 하기 어렵다(H. J. Lee, 2017). 어떠한 환경 적 자극에 의해 스트레스를 경험하였을 때 이를 왜곡하여 해 석하고 과도한 스마트폰 사용으로 스트레스를 해소하지 않으 려면 가족의례를 통한 가족 구성원 간의 건강한 소통과 상호 작용이 스트레스를 완화시키거나 대안을 마련하는데 기여할 수 있을 것이다. 선행연구에 따르면, 가족의 응집성이 높고 부 모와의 의사소통 및 가족관계가 긍정적일수록 자녀의 스마트 폰 의존도도 낮아지는 경향을 보였다(Yuh, 2015). 결국 동일한 수준의 부정적 자동적 사고를 보이는 아동일지라도 가족 구성 원과 함께 하는 주말의 가족의례를 경험하는 정도에 따라서 스마트폰 의존도에 있어서 차이가 있을 것으로 추론할 수 있 다. 따라서 본 연구에서는 아동의 부정적 자동적 사고가 스마 트폰 의존도에 미치는 영향을 가족의례 중 주말가족활동 의례 가 조절하는지에 대해서 알아보고자 한다. 본 연구의 목적을 위해 설정한 연구문제는 다음과 같다.

\section{연구문제 1}

아동의 부정적 자동적 사고가 스마트폰 의존도에 영향을 미 치는가?

\section{연구문제 2}

아동의 부정적 자동적 사고와 스마트폰 의존도 간의 관계를 주말가족활동 의례가 조절하는가?

\section{Methods}

\section{연구대상}

본 연구의 대상은 서울특별시 소재의 초등학교 3곳과 인천광 역시 소재의 초등학교 2곳에 재학 중인 초등학교 5-6학년 274 명(남아:128명, 여아:126명)이다(Table 1). 본 연구에서 편의표 집(convenience sampling)을 이용하여 서울과 인천 내에서 임의 로 선정한 지역에 위치한 초등학교들을 무작위로 컨택한 뒤 
Table 1

Characteristics of Participants

\begin{tabular}{|c|c|}
\hline Variables & $n(\%)$ \\
\hline \multicolumn{2}{|l|}{ Sex } \\
\hline Male & $128(46.7)$ \\
\hline \multicolumn{2}{|l|}{ Grade level } \\
\hline $5^{\text {th }}$ grade & $147(53.6)$ \\
\hline \multicolumn{2}{|l|}{ Smartphone use hours a day } \\
\hline Less than a hour & $88(32.1)$ \\
\hline $\begin{array}{l}\text { More than } 1 \text { hour and } \\
\text { less than } 2 \text { hours }\end{array}$ & $84(30.7)$ \\
\hline $\begin{array}{l}\text { More than } 2 \text { hours and } \\
\text { less than } 3 \text { hours }\end{array}$ & $48(17.5)$ \\
\hline More than 4 hours & $25(9.1)$ \\
\hline \multicolumn{2}{|l|}{ Ownership of a smartphone a child uses } \\
\hline Child & $241(88.0)$ \\
\hline Mother & $19(6.9)$ \\
\hline Father & $7(2.6)$ \\
\hline Sibling & $1(0.4)$ \\
\hline No response (missing data) & $6(2.2)$ \\
\hline
\end{tabular}

Note. $N=274$.

연구 참여에 동의한 초등학교들을 선택하였다. 본 연구는 최 근 스마트폰 보유율의 급격한 증가세를 보이고 있는 초등학교 고학년 군을 대상으로 진행하였다. 스마트폰을 과도하게 또 는 의존적으로 사용하는 행동은 사용자 나이와 상관없이 논 의되어야 할 중요한 이슈이지만 특히 아동기에서 초기 청소년 기로 접어드는 초등학생 고학년을 중심으로 살펴보려 하는 이 유는 다음과 같다. 첫째, 초등학교 고학년 군은 아동기 후기에 서 초기 청소년기로 넘어가는 시기로 서로 다른 특성이 있는 발달 단계가 중첩되면서 그에 따른 여러 변화를 경험하게 된 다. Piaget의 인지발달이론에 따르면 구체적 조작기에서 형식 적 조작기로 넘어가는 시기(Berk, 2005/2008)이며 Erickson의 심리·사회적 발달이론에 따르면 성실성 대 열등감 단계에서 정체성 대 역할 혼동 단계로 넘어가는 시기(Berk, 2005/2008) 이다. 즉, 발달에 따른 변화로 인해 인지적, 사회적, 정서적 혼 란을 경험할 수 있으며 이때의 경험은 후에 청소년기 발달 양 상에 많은 영향을 주기 때문에 이 시기 아동들의 스마트폰 사 용에 관한 연구가 필요하다. 둘째, 초등학교 고학년 집단의 스 마트폰 보유율이 저학년 집단보다 현저하게 높고 중학생 집단 의 보유율과 큰 차이가 없는 것으로 보아(KISDI, 2018) 초등학
교 고학년 집단 아동들의 스마트폰 사용은 초등학교 저학년 집단과는 다른 특성적 구분을 보이며 급증한 스마트폰 보유율 로 인해 고학년 집단 아동들이 스마트폰 사용의 부정적 영향을 경험할 가능성이 크기 때문이다. 연구대상자 중 $88 \%$ 가 자신의 스마트폰을 보유하고 있었고, 나머지 $12 \%$ 는 부모나 형제자매 의 스마트폰을 사용하고 있었다. 자신의 스마트폰을 보유하고 있지 않은 영유아기에도 스마트폰 과의존 증상이 나타난다는 연구결과 $(\mathrm{Na}, 2013)$ 로 미루어보아 스마트폰 소유 여부는 스마 트폰 의존도에 큰 영향을 미치지 않는 것으로 볼 수 있다. 따라 서 본 연구에서는 자신의 스마트폰을 소유한 아동과 부모 및 형제자매의 스마트폰을 사용하는 아동들을 모두 연구 대상에 포함하였다. 연구 대상인 아동의 절반 이상 $(32.1 \%+30.7 \%)$ 이 하루에 2 시간미만으로 스마트폰을 사용한다고 응답하였다.

\section{연구도구}

\section{부정적 자동적 사고}

아동의 부정적 자동적 사고의 정도를 측정하기 위하여 Hollon 
과 Kendall (1980)이 개발한 자동적 사고 질문지(Automatic Thoughts Questionnaire [ATQ-N])를 Yang, Hong, Jung과 Kim (2005)이 국내 청소년 집단을 대상으로 타당화 한 설문지를 사 용하였다. 이 도구는 총 30 문항이며 자기 보고식 척도이다. 각 문항에 제시된 부정적인 사고를 지난 일주일 동안 얼마나 떠 올렸는지에 대해 5점 Likert 척도를 사용하여 평정하도록 하였 고 척도의 평균점수를 최종분석에 사용하였다. 부정적 자동적 사고 척도는 "나는 나를 싫어한다.", "나는 무기력하다.", "나 는 새로운 일을 시작할 수 없다.”는 것과 같은 문항들로 구성 되어 있다. 점수가 높을수록 부정적 자동적 사고를 하는 경향 이 높음을 나타낸다. 본 연구에서 사용된 부정적 자동적 사고 척도의 신뢰도 계수 Cronbach's $\alpha$ 는 .97로 나타났다.

\section{주말가족활동 의례}

주말가족활동 의례(weekend family rituals) 경험의 정도를 측정 하기 위하여 Fiese와 Kline (1993)이 개발한 가족의례 질문지 (Family Ritual Questionnaire [FRQ])를 E. Y. Kim과 Park (2013) 이 번안하여 사용한 척도를 $\operatorname{Han}$ (2018)이 수정.보완한 것을 사 용하였다. Fiese와 Kline (1993)이 개발한 가족의례 종류 7가지 (저녁식사 의례, 주말가족활동 의례, 휴가 의례, 가족 기념일 의례, 가족 모임 의례, 명절 의례, 종교 의례) 중에서 본 연구에 서는 주말가족활동 의례 경험의 정도를 묻는 문항을 사용하였 다. 대표적인 문항으로는 "주말(휴일)에 가족들과 함께 하는 정해진 활동이 있다.”, “주말(휴일)에 가족과 함께 시간을 보낸 다.", “주말(휴일)에 함께 할 활동에 대해 가족들과 의논한다.", "가족과 주말(휴일)을 함께 보냄으로써 '우리 가족'이라는 특 별한 느낌을 갖는다."와 같은 문항이 있으며, 주말가족활동 의 례 경험은 총 6 문항으로 구성되어 있다. 각 문항에 대해 Likert 5점 척도를 사용하여 평정하도록 하였다. 즉, 점수가 높을수록 아동이 주말가족활동 의례를 많이 경험하는 것을 의미한다. 본 연구에서 사용된 주말가족활동 의례 척도의 신뢰도 계수 Cronbach's $\alpha$ 는 .89였다.

\section{스마트폰 의존도}

아동의 스마트폰 의존도를 측정하기 위하여 한국지능정보사 회진흥원(National Information Society Agency; D. Kim et al., 2011)에서 개발한 청소년 대상의 스마트폰 의존도 척도를 사 용하였다. 본 척도 점수에 따라 고위험군, 잠재적 위험군 그리 고 일반 사용자군으로 분류할 수 있다. 미래창조과학부와 한
국정보화진흥원(Ministry of Science, ICT and Future Planning \& National Information Society; Kwon, Nam, \& Seo, 2014)의 인 터넷 중독 실태조사에 따르면, 본 도구를 사용하여 만 10-19세 청소년 5,967명을 대상으로 스마트폰 중독 정도를 측정하였 는데 스마트폰 중독 평균은 $2.2(S D=0.2)$ 로 보고하였다. 스마 트폰 의존 척도는 '내성' '금단' '일상생활장애' '가상세계지향 성'이라는 4 개의 하위요인으로 구성되며 각 문항은 5점 Likert 척도를 사용하여 평정한다. 대표적인 문항으로는 “스마트폰 의 지나친 사용으로 학교 성적이 떨어졌다.", “스마트폰을 사 용할 수 없게 된다면 견디기 힘들 것이다.” 등이 있다. 이 중 8 번 문항은 역채점하였다. 본 연구에서 사용한 스마트폰 과의 존 척도의 신뢰도 계수 Cronbach's $\alpha$ 는 .90으로 나타났다. 문항 들의 요인분석을 위해 베리맥스 회전방식과 주성분 분석 방식 을 사용하였다. 그 결과 원척도와 달리 하위요인이 2 개로 나타 났으면 그중 계수가 낮은 문항 1개(문항번호 8번 “스마트폰 사 용시간을 스스로 조절할 수 있다.”)를 삭제하여 총 14 문항을 최종분석에 사용하였다. 본 연구에서는 점수가 높을수록 아동 의 스마트폰 의존도가 높다는 것을 의미한다.

\section{통제변수}

본 연구에서는 선행연구에서 아동의 스마트폰 의존도에 영향 을 미치는 것으로 보고된 바 있는 변수들인 아동의 성별(남학 생 = 0, 여학생 = 1), 학년 $(5$ 학년 = 0, 6 학년 = 1), 그리고 하루 스 마트폰 사용 시간을 통제변수로 사용하였다.

\section{연구절차}

이 연구의 자료 수집은 2019년 4월 5월까지였으며 서울특별 시 초등학교 3 곳과 인천광역시 초등학교 2곳에 재학 중인 초 등학생 5, 6학년 대상으로 진행하였다. 연구 협조에 동의한 초 등학교에 설문지를 배부하였다. 배부된 설문지는 약 300 부였 으며 수거된 설문지는 279 부로 수거율은 약 $93 \%$ 였으며 불성 실하게 작성된 설문지를 5 부를 제외한 약 274 부의 설문지를 최종분석에 사용하였다.

\section{자료분석}

본 연구에서는 수집된 자료의 통계 분석을 위하여 SPSS 22.0 (IBM Co., Armonk, NY)와 PROCESS macro version 3.2 (Model 1 ; Hayes, 2017)를 사용하였다. 분석 방법은 다음과 같다. 첫째, 
연구대상자들의 일반적 특성과 변인들의 전반적인 경향을 살 펴보기 위하여 기초 통계 분석을 실시하였다. 둘째, 부정적 자 동적 사고 변인, 주말가족활동 의례 변인, 스마트폰 의존도 변 인 간의 관계를 살펴보기 위하여 상관분석을 실시하였다. 셋 째, 아동의 부정적 자동적 사고가 스마트폰 의존도에 미치는 영향을 살펴보기 위하여 선행연구에서 스마트폰 의존도에 영 향을 미치는 것으로 보고된 바 있는 변수들(성별, 학년 그리고 하루 스마트폰 사용 시간)을 통제한 뒤 아동의 부정적 자동적 사고의 영향력을 살펴보고자 위계적 회귀분석을 시행하였다. 마지막으로, 아동의 부정적 자동적 사고와 스마트폰 의존도 간의 관계를 주말가족활동 의례가 조절하는지 살펴보기 위해 통제변수들(성별, 학년 그리고 하루 스마트폰 사용 시간)을 투 입하고 위계적 회귀분석을 실시하였다.

\section{Results}

\section{주요 변인들의 전반적인 경향}

아동의 부정적 자동적 사고, 주말가족활동 의례 경험, 스마트 폰 의존도의 전반적인 경향과 상관관계를 알아보기 위하여 각 변인에 대한 평균과 표준편차 최대값 및 최소값을 알아보고 Pearson 적률상관관계분석을 실시하였고, 결과는 Table 2에 제 시하였다. 여기에서 하루 스마트폰 사용 시간 변인의 점수를 1 시간 미만 $=1$ 점, 1 시간 이상 2 시간 미만 $=2$ 점, 2 시간 이상 3 시간 미만 $=3$ 점, 3 시간 이상 4 시간 미만 $=4$ 점, 4 시간 이상 $\sim 5$ 시간 미만 $=5$ 점으로 처리하였다.

아동의 부정적 자동적 사고의 전체 평균은 $1.69(S D=.72)$ 였으며 주말가족활동 의례의 평균은 $3.54(S D=1.01)$, 스마트 폰 의존도의 평균은 $1.95(S D=.71)$ 으로 나타났다. 성별과 부 정적 자동적 사고는 유의미한 정적 상관관계를 보였다 $(r=.17$, $p<.01)$. 즉, 여아가 남아보다 부정적 자동적 사고를 더 많이 하는 것으로 나타났다.

아동의 학년은 아동의 스마트폰 하루 사용시간 $(r=.24, p<$ $.001)$ 과 스마트폰 의존도 $(r=.25, p<.001)$ 와 정적 상관을 보였 고, 주말가족활동 의례와는 부적 상관 $(r=-.14, p<.05)$ 을 보였 다. 즉, 5 학년보다 6 학년이 하루 스마트폰 사용 시간이 많으며 스마트폰 의존도도 높은 것으로 나타났다. 또한, 5 학년이 6학 년보다 주말가족활동 의례 경험 정도가 많은 것으로 나타났다.

하루 스마트폰 사용 시간은 부정적 자동적 사고 $(r=.26, p<$ $.001)$ 와 스마트폰 의존도 $(r=.53, p<.001)$ 와 유의미한 정적 상
관을 보였다. 그러나 하루 스마트폰 사용 시간 변인과 주말가 족활동 의례는 부적 상관 $(r=-.30, p<.001)$ 이 나타났다. 즉, 아 동의 하루 스마트폰 사용시간이 길수록 아동의 부정적 자동적 사고 및 스마트폰 의존도가 높아지는 것으로 드러났다. 또한, 하루 스마트폰 사용 시간이 길면 아동이 가족과 함께 하는 주 말가족활동 의례 경험의 정도는 낮아지는 경향을 보였다.

부정적 자동적 사고는 주말가족활동 의례와 부적 상관관계 $(r=-.46, p<.001)$ 를 보이지만 스마트폰 의존도와는 정적 상 관관계 $(r=.49, p<.001)$ 를 보였다. 이는 부정적 자동적 사고를 하는 경향이 높은 아동의 경우 가족과 함께하는 의미 있는 주 말가족활동 의례 경험이 적고 스마트폰을 의존적으로 사용하 는 경향은 높은 것을 의미한다. 마지막으로 주말가족활동 의 례와 스마트폰 의존도는 유의미한 부적 상관관계 $(r=-.41, p<$ .001)를 보였다. 이는 가족과 함께 하는 주말가족활동 의례를 많이 경험한 아동일수록 스마트폰을 의존적으로 사용하는 가 능성이 낮은 것을 의미한다.

\section{아동의 부정적 자동적 사고와 스마트폰 의존도 간의 관계에서 주말가족활동 의례의 조절효과}

아동의 부정적 자동적 사고가 스마트폰 의존도에 미치는 영 향에 대한 주말가족활동 의례의 조절효과를 살펴보기 위하 여 위계적 회귀분석을 실시하였다. 이때, 하루 스마트폰 사용 시간 변인의 점수를 1 시간 미만은 1점, 1 시간 이상 2 시간 미 만은 2점, 2시간 이상 3시간 미만은 3점, 3시간 이상 4시간 미만은 4점, 4시간 이상 5시간 미만은 5점으로 처리하였다. Table 3에 제시된 바와 같이 Model 1에서 연구대상의 일반적 특성 변인을 투입하였다. 그 결과 학년과 $(\beta=.14, p<.05)$ 하루 스마트폰 사용시간 $(\beta=.49, p<.001)$ 이 스마트폰 의존도에 유 의미한 영향을 미치며 Model 1은 30\%의 설명력 $(F=37.60, p<$ .001)을 보이는 것으로 나타났다.

Model 2에서는 Model 1에 투입했던 연구대상자의 일반적 특성 변인을 통제하고 독립변인으로 부정적 자동적 사고를 투 입하였다. 그 결과 Model 2 가 Model 1에 비해 $13.3 \%$ 의 유의미 한 설명력의 증가를 보였으며 총 $43 \%(F=30.85, p<.001)$ 의 설명력을 보였다. 아동의 부정적 자동적 사고가 스마트폰 의 존도에 미치는 영향에 대한 주말가족활동 의례의 조절효과를 살펴보기 전, 조절효과 검증 시 독립변수의 곱으로 만들어진 상호작용 때문에 발생하는 변인 간의 다중공선성 문제를 해결 하기 위해 각 독립변인과 조절변인의 값을 평균중심화(meancentering)한 값을 통해 구한 상호작용 값을 회귀분석에 투입하 
Table 2

Means, Standard Deviations, and Correlations Among Variables

\begin{tabular}{|c|c|c|c|c|c|c|c|c|}
\hline & 1 & 2 & 3 & 4 & 5 & 6 & $\begin{array}{c}M \\
(S D)\end{array}$ & Min - Max \\
\hline 1. Sex & - & & & & & & & \\
\hline 2. Grade level & $-0.13^{*}$ & - & & & & & & \\
\hline 3. Smartphone use hours a day & 0.03 & $0.24^{* * *}$ & - & & & & & \\
\hline 4. Negative automatic thoughts & $0.17^{* *}$ & 0.11 & $0.26^{* * *}$ & - & & & $\begin{array}{c}1.69 \\
(.72)\end{array}$ & $1-4.47$ \\
\hline 5. Weekend family rituals & -0.03 & $-0.14^{*}$ & $-0.30^{* * *}$ & $-0.46^{* * *}$ & - & & $\begin{array}{c}3.54 \\
(1.01)\end{array}$ & $1-5$ \\
\hline 6. Problematic smartphone use & 0.06 & $0.25^{* * *}$ & $0.53^{* * *}$ & $.49^{* * *}$ & $-0.41^{* * *}$ & - & $\begin{array}{c}1.95 \\
(.71)\end{array}$ & $1-4.5$ \\
\hline
\end{tabular}

Note. $N=274$. Sex is converted to the dummy variant; Boy =0, Girl=1; Grade level is converted to the dummy variant; 5 th grade $=0$, 6th grade $=1$.

${ }^{*} p<.05 .{ }^{* *} p<.01 .{ }^{* * *} p<.001$.

Table 3

The Moderating Effect of Weekend Family Rituals on the Association Between Children's Negative Automatic Thoughts and Problematic Smartphone Use

\begin{tabular}{|c|c|c|c|c|c|c|}
\hline \multicolumn{7}{|c|}{ Dependent variable } \\
\hline \multirow[t]{2}{*}{ Independent variable } & \multicolumn{6}{|c|}{ Problematic smartphone use } \\
\hline & \multicolumn{2}{|c|}{ Model 1} & \multicolumn{2}{|c|}{ Model 2} & \multicolumn{2}{|c|}{ Model 3} \\
\hline \multirow[t]{2}{*}{ Constant } & \multirow{2}{*}{$\begin{array}{c}1.18 \\
B(S E)\end{array}$} & \multicolumn{3}{|c|}{1.38} & \multicolumn{2}{|c|}{1.46} \\
\hline & & $\beta$ & $B(S E)$ & $\beta$ & $B(S E)$ & $\beta$ \\
\hline Sex & $.09(.07)$ & .07 & $.02(.07)$ & .01 & $.01(.06)$ & .01 \\
\hline Grade level & $.19(.07)$ & $.14^{*}$ & $.15(.07)$ & $.10^{*}$ & $.14(.07)$ & $.10^{*}$ \\
\hline Smartphone use hours a day & $.27(.03)$ & $.49^{* * *}$ & $.21(.03)$ & $.38^{* * *}$ & $.21(.03)$ & $.38^{* * *}$ \\
\hline \multicolumn{3}{|l|}{ Negative automatic thoughts (A) } & $.30(.05)$ & $.31^{* * *}$ & $.42(.06)$ & $.43^{* * *}$ \\
\hline \multicolumn{3}{|l|}{ Weekend family rituals (B) } & $-.09(.04)$ & $-.14^{*}$ & $-.09(.04)$ & $-.14^{* *}$ \\
\hline \multicolumn{5}{|l|}{$\mathrm{A} \times \mathrm{B}$} & $.20(.04)$ & $.24^{* * *}$ \\
\hline$R^{2}\left(\right.$ Adjusted $\left.R^{2}\right)$ & \multicolumn{2}{|c|}{$.30(.30)$} & \multicolumn{2}{|c|}{$.43(.42)$} & \multicolumn{2}{|c|}{$.47(.46)$} \\
\hline$\triangle R^{2}$ & \multicolumn{2}{|c|}{-} & \multicolumn{2}{|c|}{$.133^{* * *}$} & \multicolumn{2}{|c|}{$.042^{* * *}$} \\
\hline$F$ & \multicolumn{2}{|c|}{$37.60^{* * *}$} & \multicolumn{2}{|c|}{$30.85^{* * *}$} & \multicolumn{2}{|c|}{$21.50^{* * *}$} \\
\hline
\end{tabular}

Note. $N=274$. Sex is converted to the dummy variant; Boy =0, Girl = 1; Grade level is converted to the dummy variant; 5 th grade $=0$, 6th grade $=1$.

${ }^{*} p<.05 .{ }^{* *} p<.01 .{ }^{* * *} p<.001$.

였다. Model 3에는 이전에 투입됐던 변인들을 통제하고 부정 적 자동적 사고와 주말가족활동 의례의 상호작용항을 추가하 였다. 그 결과 부정적 자동적 사고와 주말가족활동 의례 변인 의 상호작용항이 유의미한 영향을 미치는 것으로 나타나 $(\beta=$ $.24, p<.001)$ 아동의 부정적 자동적 사고와 스마트폰 의존도 와의 관계를 아동이 경험한 주말가족활동 의례 경험이 조절하 는 것을 확인할 수 있었다. 또한 Model 3에서는 Model 2에 비 해 $4.2 \%$ 의 유의미한 설명력 $(F=21.50, p<.001)$ 의 증가를 보
이며 총 $47 \%$ 의 설명력을 보였다.

이러한 결과는 동일한 수준의 부정적 자동적 사고를 하는 아동이더라도 주말가족활동 의례 경험이 많은 경우 주말가족 활동 의례 경험이 적은 아동에 비해 스마트폰 의존도가 낮은 것을 의미한다. 다시 말해, 부정적 자동적 사고를 많이 하는 아 동일수록 스마트폰을 의존적으로 사용하는 경향이 높아지지 만, 이때 아동이 주말마다 가족과 함께 하는 의미 있는 활동을 규칙적으로 경험하는 경우가 많아지면 아동이 스마트폰을 의 
존적으로 사용하는 경향은 감소한다는 것이다. 아동의 부정 적 자동적 사고가 스마트폰 의존도에 미치는 영향에서 주말가 족활동 의례의 조절효과를 그래프로 나타내면 Figure 1과 같 다. Figure 1 은 주말가족활동 의례의 정도(낮음, 중간, 높음)에 따라서 부정적 사고가 스마트폰 의존에 미치는 영향이 달라지 는 것을 보여주며, 주말가족활동 의례는 가족의례 점수의 평 균 $-1 S D$, 평균, 평균 $+1 S D$ 로 나누어서 분석하였다. 흥미로운 점은 아동의 부정적 자동적 사고가 낮을수록 주말가족활동 의 례의 조절효과가 높은 반면에, 아동의 부정적 자동적 사고가 높아질수록 주말가족활동 의례의 조절효과는 낮아지는 것을 그래프를 통해 확인할 수 있다. 세 집단의 기울기를 살펴보면, 주말가족활동 의례 경험이 낮은 집단의 경우 기울기가 .62 (스 마트폰 의존 $=1.37+.62 \times$ 부정적 자동적 사고)이고, 평균 집 단은 1.13 (스마트폰 의존 $=1.14+1.13 \times$ 부정적 자동적 사고), 주말가족활동 의례 경험이 높은 집단의 기울기는 1.42 (스마 트폰 의존 $=1.01+1.42 \times$ 부정적 자동적 사고)로 나타나서 주 말가족활동 의례 경험이 많을수록 조절효과가 높은 것을 확인 할 수 있다. 즉, 아동의 부정적 자동적 사고 수준이 낮은 경우 주말가족활동 의례가 부정적 자동적 사고가 스마트폰 의존에 미치는 영향력을 완화시키는 효과가 뚜렷하나, 부정적 자동적 사고 수준이 높은 경우에는 주말가족활동 의례가 부정적 자동 적 사고가 스마트폰 의존에 미치는 부정적 영향력을 완화시키 는 효과가 미비한 것으로 보인다. 아동의 스마트폰 의존에 미 치는 부정적 자동적 사고의 영향력 $(\beta=.43, p<.001)$ 이 주말가 족활동 의례의 영향력 $(\beta=-.14, p<.01)$ 보다 상대적으로 큰 것 을 고려할 때 부정적 자동적 사고의 수준이 높을수록 주말가 족활동 의례가 부정적 자동적 사고의 부정적 영향력을 상쇄하 기 어려운 것을 알 수 있다.

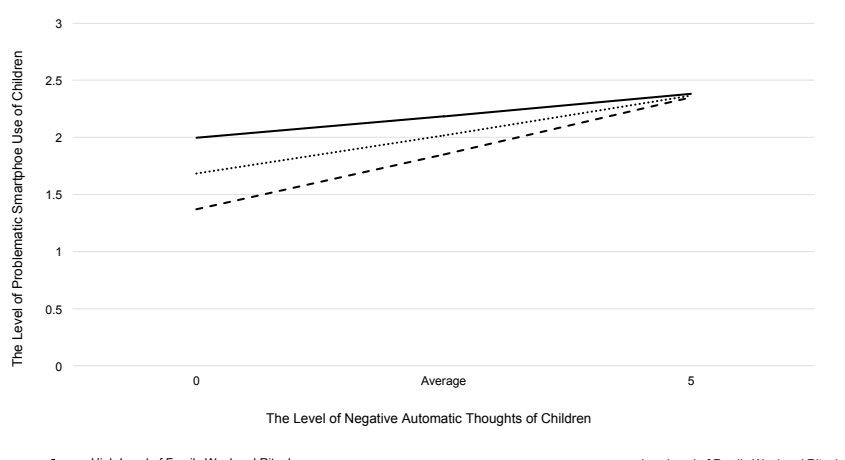

Figure 1. The moderating effect of weekend family rituals on the association between children's negative automatic thoughts and problematic smartphone use.

\section{Discussion}

본 연구는 초등학생 5-6학년을 대상으로 아동의 부정적 자동 적 사고가 아동의 스마트폰 의존도에 미치는 영향에 대한 주 말가족활동 의례의 조절효과를 검증하였다. 그 결과, 아동의 부정적 자동적 사고와 가족들과의 주말가족활동 의례 경험은 아동의 스마트폰 의존도를 예측하는 유의미한 변인으로 밝혀 졌다. 또한, 아동이 가족들과 경험한 주말가족활동 의례는 아 동의 부정적 자동적 사고와 스마트폰 의존도 간의 관계를 조 절하는 것으로 나타났다. 본 연구에서 설정한 연구문제에 대 한 검증결과들을 토대로 논의 및 제언을 하자면 다음과 같다.

첫째, 본 연구에서는 아동의 부정적 자동적 사고가 스마트 폰 의존도에 유의미한 영향을 미치는 것으로 나타났다. 이는 아동이 부정적 자동적 사고를 많이 할수록 스마트폰을 의존적 으로 사용한다는 것을 의미한다. 부정적 인지 도식을 가진 아 동은 특정 상황이나 사건을 접했을 때 관련 인지도식이 활성화 되고 이에 아동은 의식하지 못할 정도의 빠른 속도로 자기 자 신을 왜곡하여 평가하게 되는 부정적 자동적 사고를 하게 된 다(Segal, 1988). Beck과 Alford (2009)는 부정적 자동적 사고를 하는 사람들이 “즉각적인 만족감을 주지 않는 활동을 피하거 나" 또는 “수동적인 오락 활동”을 하는 모습을 보인다고 주장 하였다. 여기서 부정적 자동적 사고를 하는 아동에게는 시간 과 장소에 상관없이 사용할 수 있는 스마트폰이 선택하기 쉬운 대안이 된다. 즉 부정적 자동적 사고로 인하여 현실을 회피하 기 위해 스마트폰을 지속적으로 사용하게 되면 이는 스마트폰 에 대한 과도한 의존으로 연결될 가능성이 커진다. 이러한 결 과는 자신에 대해 부정적으로 평가하는 개인이 이를 극복하기 위한 대안으로서 왜곡된 행동을 선택하고 이를 반복하면서 중 독 경향적 행위를 하게 된다는 Bowler 등(2011)의 주장과도 같 은 맥락이라 할 수 있다. 또한, 청소년의 부정적인 인지사고나 평가는 스마트폰 의존으로 이어질 수 있다는 기존의 선행연구 (H. N. Lee \& Kim, 2018; H. Y. Lee \& Lee, 2019; Y. Yoon \& Kim, 2019)들도 이를 뒷받침한다. 또한, 본 연구의 결과는 인터넷 접 속을 위해 이용하는 매체가 $\mathrm{PC}$ 에서 스마트폰으로 바뀐 것일 뿐, 자기 자신에 대한 부적응적 인지 사고를 하는 사용자가 인 터넷을 병리적으로 사용한다는 Davis (2001)의 주장과도 같은 맥락에서 해석할 수 있다. 이는 인터넷에 접속하기 위해 사용 하는 매체가 PC에서 스마트폰으로 바뀌어가는 최근 미디어 기 기 사용 실태를 고려하였을 때 과거 인터넷의 과도한 사용이나 중독적 사용에 영향을 미친다고 밝혀졌던 요인들이 스마트폰 의존도에도 영향을 미칠 수 있음을 시사한다. 
둘째, 아동이 주말에 규칙적으로 가족과 함께 활동하는 가 족의례 경험은 아동의 부정적 자동적 사고와 스마트폰 의존 도 간의 관계를 조절하는 것으로 나타났다. 이는 주말가족활 동 의례가 아동이 부정적 자동적 사고를 함에 따라 스마트폰 을 더 의존적으로 사용하게 되는 것을 어느 정도 완화해주고 있음을 의미한다. 이러한 연구 결과는 가족의례가 자녀의 외 재적.내재적 문제행동을 감소시켰다는 Malaquias 등(2015)의 연구와 저녁 시간 가족의례가 어머니의 양육스트레스가 아동 의 행복과 안녕감에 미치는 부정적 영향력을 완화시킨다는 Y. Yoon 등(2015)의 연구와 맥락을 같이 한다. 이처럼 본 연구에 서는 주말가족활동 의례가 아동의 스마트폰 의존에 기인하는 아동의 인지적 요인인 부정적 자동적 사고의 부정적인 영향력 에 대해 완충 작용을 하고 있음을 밝혔다.

주말가족활동 의례가 부정적 자동적 사고와 스마트폰 의존 의 관계를 조절하는 것은 가족의례가 갖는 특성과 관련이 있 을 수 있다. 가족의례는 최소 두 명 이상의 가족 구성원들을 포 함하여 규칙적으로 실행되는 것(Fiese et al., 2002)으로서 가족 구성원들은 가족의례를 통해서 의미 있는 상호작용을 하게 된 다. 여기서 가족 구성원들이 느끼는 의미란 오랜 시간 동안 가 족 내에서 형성되어 구성원들에게 전달되는 공유된 신념이라 할 수 있다(Malaquias et al., 2015). 이 의미를 통해서 '우리는 가 족'이라는 유대감을 갖게 되는 것이다. 따라서 가족의례는 가 족 내에서 이루어지는 비교적 안정적인 소통 방식이라고 할 수 있으며 가족의례를 통해 형성된 유대감을 토대로 가족들 은 스트레스 사건이 발생했을 때 가족으로부터 사회적 지지를 얻고(Howe, 2002), 스트레스 사건과 함께 수반되는 여러 부정 적인 정서들을 극복해낼 수 있는 것이다. 왜냐하면, 가족의례 를 실행하게 되면 필연적으로 아동은 가족과 이야기를 나누게 되고, 자기 생각이나 경험을 털어놓을 기회를 얻게 되고 자신 의 생각이나 행동에 대한 피드백을 가족으로부터 받을 수 있 기 때문이다. 이를 통해 아동은 가족들로부터 지지를 받을 수 있다는 믿음을 형성하고(Howe, 2002), 가족들과 유대감을 형 성하게 된다(Eaker \& Walters, 2002). 이로써 아동은 자신이 갖 고 있던 부정적인 사고들을 의식적 수준으로 끌어올려 인식하 게 되고 이를 나름대로 재구조화함으로써 자신의 왜곡된 인지 사고방식을 수정할 수 있게 된다. 이는 인지 치료에서 개인의 인지 도식에 의한 부정적 자동적 사고와 같은 인지적 왜곡, 인 지적 오류나 편향을 스스로 인식할 수 있도록 지원하고 이것 들을 바로 잡아 인지 도식을 재구조화(Beck \& Alford, 2009)하 는 것과도 유사하다. 다양한 가족의례 중 하나의 유형인 주말 가족활동 의례 역시 주말마다 규칙적으로 수행되는 가족 단위
활동으로 가족 간의 응집력과 유대감을 증진시키기 때문에, 주말가족활동 의례를 통한 가족들과의 상호작용은 부정적 자 동적 사고로 인하여 현실 외면의 수단으로 스마트폰이란 대안 을 찾는 경향을 감소시킬 수 있다. 이처럼 주말마다 가족과 함 께 하는 활동을 통해서 평일의 바쁜 일상에서 벗어나 비교적 여유로운 주말에 아동은 가족과의 관계를 다시 확인할 수 있 게 되고 이 활동에서 이루어진 가족 간의 상호작용은 아동이 자신의 행동을 지각하고 수정할 기회를 제공할 수 있다.

다만, 본 연구에서 아동의 부정적 자동적 사고의 수준이 높 아질수록 주말가족활동 의례의 조절 효과가 미비해지는 것으 로 나타났다. 이는 아동의 부정적 자동적 사고로 인한 스마트 폰 의존이 부정적 자동적 사고 수준이 너무 높을 경우에는 가 족 구성원 간의 소통과 유대감만으로는 극복되기 어려움을 의 미한다. 따라서 이 경우 스마트폰 의존도를 낮추기 위해서 부 정적 자동적 사고의 수준을 낮출 수 있는 또 다른 외부적 개입 이 필요할 수 있다.

본 연구 결과를 토대로 정책적 제언을 하자면 다음과 같다. 첫째, 스마트폰 의존 예방 교육에 자기 자신에 대해서 생각해 보는 기회를 제공하는 내용을 포함하는 것이 필요하다. 본 연 구는 스마트폰 과의존 예방 교육 내용에 아동이 생각하는 자 기 자신은 어떤지, 자신의 기분이 안 좋을 때 또는 스트레스를 풀기 위해서 어떻게 하는지에 대해서 생각해보는 내용을 포 함하는 것을 제안한다. Beck과 Alford (2009)이 제안한 인지치 료적 접근에서는 자신이 가진 자동적 사고를 의식적 수준으로 가져와 개인이 인식할 수 있도록 몇 주에 걸쳐 질문하고 피드 백하는 과정을 갖는다. 이를 통해서 왜곡된 인지 도식을 재구 조화하여 편향된 인지 사고방식을 수정하는 것이다. 인지 치 료의 방법적 틀을 아동의 스마트폰 예방 교육에 적용하여 이 처럼 자신에 대해서 생각해보고 자신의 스마트폰 사용 패턴에 대해 아동 스스로가 생각해볼 기회(J. H. Park, 2019)를 제공해 보는 것도 좋을 것이다.

둘째, 주말가족활동 의례로 활용할 수 있는 다양한 활동 방 법을 개발하고 적극적으로 안내할 것을 제안한다. 최근 사회 전반적으로 가족의 여가에 대한 중요성이 강조되고 있다. 주 말가족활동 의례를 안내할 때에는 첫째, 가족들의 '협의'를 통 해 매주 주말마다 함께 할 활동을 결정해야한다는 점과 둘째, 가족들이 서로 가족이라는 소속감과 유대감을 공유할 수 있는 ‘의미'있는 활동이어야 한다는 점을 중심으로 하여 일반적인 여가와는 구분되는 가족의례의 특성이 잘 드러나도록 해야 한 다. 학교에서는 주말가족활동 의례의 개념과 특성 그리고 효 과에 대한 부모교육 자료를 체계적으로 배부하고 아동들이 가 
정에서 가족들과 상의하여 주말가족활동 의례를 계획하여 실 시하거나 이미 실행 중인 주말가족활동 의례를 부모와 아동에 게 소개할 수 있다. 또한, 가족과 함께 하는 의례적 활동에 대 하여 아동이 자신의 생각과 느낌을 발표해보는 경험을 통해 아동이 가족의례에 좀 더 친숙해질 수 있도록 지원할 수 있다.

셋째, 주말가족활동 의례뿐만 아니라 평일에도 가족들이 함께할 수 있는 가족의례를 개발할 수 있도록 사회적 환경을 조성할 필요가 있다. 최근 몇 년간 일과 가정의 양립이라는 제 도적.사회적 청사진이 제시되고 있으나 아직은 평일 저녁에 가족들이 모여 함께 저녁식사를 하거나 대화하는 것조차 어려 운 것이 현실이다. 나아가 가족들과 함께 어떻게 시간을 보내 야 하는지 모르는 사람들도 많다. 이러한 현 상황에서 가족의 례는 가족들에게 의미와 안정감을 제공하기 위해서는 규칙적 으로 실행되어 예측 가능한 특성으로 인해 많은 장점을 가져 다줄 수 있다. 주말가족활동 의례 뿐 아니라 다른 종류의 가족 의례를 형성할 수 있으려면 주말 이외에도 가족들이 함께 보 낼 수 있는 시간이 많아져야 하며 이 시간을 어떻게 보낼 것인 가에 대한 적극적인 안내 또는 교육도 함께 제공되는 등의 사 회 구조적인 개선이 필요하다.

본 연구의 한계점은 다음과 같다. 첫째, 본 연구의 자료 수 집은 연구대상인 초등학생 5-6학년의 자기보고(self report) 형 식으로 이루어졌기 때문에 수집할 수 있는 데이터 종류에 제 한이 있었다. 특히 본 연구에서 사용한 설문지에는 연구대상 자 아동 부모의 사회·경제적 변인에 대한 문항이 포함되어 있 었으나 이에 대해 무응답 한 설문지가 다수 있어 부모의 사회. 경제적 변인에 관해 분석에 사용할 수 있을 정도의 충분한 자 료를 수집할 수 없었다. 특히 아동이 설문지에 응답을 하였기 때문에 가구 소득이나 경제 상태에 대한 객관적인 정보를 수 집하기 어려워서 이를 분석에서 제외하였다. 둘째, 본 연구에 서 사용한 부정적 자동적 사고 척도는 국내 청소년을 대상으 로 타당화 연구에서 사용한 척도를 사용하였다. 학자에 따라 서 초등학교 5-6학년을 초기 청소년기로 보기도 하지만 그렇 지 않은 때도 있기에 해당 척도를 사용한 것은 본 연구의 한계 점이 될 수 있다.

본 연구 결과를 토대로 후속 연구를 위한 제언을 하면 다음 과 같다. 첫째, 후속연구에서는 초등학생 5-6학년 이하의 아동 또는 청소년을 포함하여 연구 대상의 범위를 확대할 수 있다. 스마트폰 의존은 나이에 상관없이 다루어져야 할 주제이기 때 문에, 유아, 청소년, 성인들을 대상으로 부정적 자동적 사고가 이들의 스마트폰 의존에 영향을 미치는지와 주말가족활동 의 례가 부정적 자동적 사고와 스마트폰 의존의 관계를 조절하는
지에 대해 조사할 필요가 있다. 둘째, 국내 가족의 다양한 특성 을 고려하여 주말가족활동 의례 외의 다른 유형의 가족의례에 관해서 연구할 필요가 있다. 가족들의 체계적 특성을 고려하 지 않고 여러 종류의 가족의례가 갖는 상대적인 영향력에 대 해서 알아본 선행연구(Bae, 2016; Han, 2018)들은 있었지만 이 연구들은 가족체계의 특성을 고려하지 않았다. 또한, 사회적 변화에 따라 가족의 특성도 변화하고 있는 만큼 다양한 종류 의 가족의례가 실행되고 있을 것이라 추측할 수 있다. 따라서 주말가족활동 의례 외에 다른 유형의 가족의례가 스마트폰 의 존도를 완화시킬 수 있는지에 대해 알아볼 수 있다.

\section{Notes}

This article is a part of the first author's Master's thesis submitted in 2020, and was orally presented at the 2021 Annual Spring Conference of the Korean Association for Children's Media \& Education.

\section{Conflict of Interest}

No potential conflict of interest relevant to this article was reported.

\section{Ethics Statement}

All procedures of this research were reviewed by IRB (KHSIRB-18043-1(RA)).

\section{References}

\section{In English}

Beck, A. T., \& Alford, B. A. (2009). Depression: Causes and treatment (2nd ed.). Philadelpia, PA: University of Pennsylvania Press.

Beck, A. T. (1976). Cognitive therapy and the emotional disorders. Madison, CT: International Universities Press.

Bianchi, A., \& Phillips, J. G. (2005). Psychological predictors of problem mobile phone use. CyberPsychology \& Behavior, 8(1), 39-51. doi:10.1089/cpb.2005.8.39

Bowler, J. L., Bowler, M. C., \& James, L. R. (2011). The cognitive 
underpinnings of addiction. Substance Use \& Misuse, 46(8), 1060-1071. doi:10.3109/10826084.2011.552934

Buchbinder, M., Longhofer, J., \& McCue, K. (2009). Family routines and rituals when a parent has cancer. Families, Systems, \& Health, 27(3), 213-227. doi:10.1037/a0017005

Chen, C., Zhang, K. Z., Gong, X., Zhao, S. J., Lee, M. K., \& Liang, L. (2017). Examining the effects of motives and gender differences on smartphone addiction. Computers in Human Behavior, 75, 891-902. doi:10.1016/j.chb.2017.07.002

Davis, R. A. (2001). A cognitive-behavioral model of pathological internet use. Computers in Human Behavior, 17(2), 187195. doi:10.1016/S0747-5632(00)00041-8

Eaker, D. G., \& Walters, L. H. (2002). Adolescent satisfaction in family rituals and psychosocial development: A developmental systems theory perspective. Journal of Family Psychology, 16(4), 406-414. doi:10.1037/08933200.16.4.406

Elhai, J. D., Tiamiyu, M. F., Weeks, J. W., Levine, J. C., Picard, K. J., \& Hall, B. J. (2018). Depression and emotion regulation predict objective smartphone use measured over one week. Personality and Individual Differences, 133, 2128. doi:10.1016/j.paid.2017.04.051

Fiese, B. H., \& Kline, C. A. (1993). Development of the family ritual questionnaire: Initial reliability and validation studies. Journal of Family Psychology, 6(3), 290-299. doi:10.1037/0893-3200.6.3.290

Fiese, B. H., Tomcho, T. J., Douglas, M., Josephs, K., Poltrock, S., \& Baker, T. (2002). A review of 50 years of research on naturally occurring family routines and rituals: Cause for celebration? Journal of Family Psychology, 16(4), 381-390. doi:10.1037/0893-3200.16.4.381

Hayes, A. F. (2017). Introduction to mediation, moderation, and conditional process analysis: A regression-based approach (2nd ed.). New York: Guilford Press.

Howe, G. W. (2002). Integrating family routines and rituals with other family research paradigms: Comment on the special section. Journal of Family Psychology, 16(4), 437-440. doi:10.1037/0893-3200.16.4.437

Kim, D., \& Jahng, K. E. (2019). Children's self-esteem and problematic smartphone use: The moderating effect of family rituals. Journal of Child and Family Studies, 28, 3446-3454. doi:10.1007/s10826-019-01526-1

Kiser, L. J. (2007). Protecting children from the dangers of urban poverty. Clinical Psychology Review, 27(2), 211-225. doi:10.1016/j.cpr.2006.07.004

Lee, H., \& Kim, J. (2018). A structural equation model on Korean adolescents' excessive use of smartphones. Asian Nursing Research, 12(2), 91-98. doi:10.1016/j.anr.2018.03.002

Malaquias, S., Crespo, C., \& Francisco, R. (2015). How do adolescents benefit from family rituals? Links to social connectedness, depression and anxiety. Journal of Child and Family Studies, 24, 3009-3017. doi:10.1007/s10826-0140104-4

Markson, S., \& Fiese, B. H. (2000). Family rituals as a protective factor for children with asthma. Journal of Pediatric Psychology, 25(7), 471-480. doi:10.1093/jpepsy/25.7.471

Segal, Z. V. (1988). Appraisal of the self-schema construct in cognitive models of depression. Psychological Bulletin, 103(2), 147-162. doi:10.1037/0033-2909.103.2.147

Shadrikov, V. D., \& Kurginyan, S. S. (2017). Propositions toward the development of a psychological theory of thought. Psychology in Russia: State of the Art, 10(1), 211-224. doi:10.11621/ pir.2017.0115

von Bertalanffy, L. (1968). General system theory: Foundations, development, applications. New York: G. Braziller.

Yoon, Y., Newkirk, K., \& Perry-Jenkins, M. (2015). Parenting stress, dinnertime rituals, and child well-being in workingclass families. Family Relations, 64(1), 93-107. doi:10.1111/ fare. 12107

Young, K. S. (1998). Internet addiction: The emergence of a new clinical disorder. CyberPsychology \& Behavior, 1(3), 237244. doi:10.1089/cpb.1998.1.237

\section{In Korean}

Bae, J.-H. (2016). The effects of family rituals on family strengths. Journal of The Korea Contents Association, 16(12), 622-635. doi:10.5392/JKCA.2016.16.12.622

Berk, L. E. (2008). Child development (7th ed.; Lee, J., Rhee, O., Shin, E., \& Ann, S. Trans.). Seoul: Sigmapress. (Original work published in 2005)

Byun, H.-S., \& Kweon, S.-Y. (2014). The effect of elementary school students' loneliness on school life adaptation: The mediating effect of smartphone addiction. The Journal of Child Education, 23(4), 303-317.

Choi, D.-H. (2019). A study on the actual condition of smartphone usage and the influential variables of 3 to 5 years old children. Journal of The Korea Society of Computer and Information, 24(2), 179-184. doi:10.9708/jksci.2019.24.02.179

Chung, K.-S., Son, H.-H., \& Yoon, G.-J. (2015). A study on the perceptions and realities of family rituals of family with children in early childhood. Korean Journal of Early Childhood Education, 35(2), 337-368. doi:10.18023/ kjece.2015.35.2.015

Han, H. J. (2018). The effects of parental monitoring, leisure activities and family ritual experiences on the over-reliance on smartphones among school-aged children: The mediation of the mobile device usage (Master's thesis). Retrieved from http:// www.riss.kr/link?id=T14914347 
Hwang, G.-W., Cho, Y.-J., \& Hyun, M.-H. (2016). The mediating effect of school adjustment on the relationship between attachment to peer and mobile phone dependency. Korean Journal of Youth Studies, 23(8), 219-239. doi:10.21509/ KJYS.2016.07.23.8.219

Hwang, S., \& Lee, Y. (2018). The mediating effects of school adjustment on the relationship between middle school students' depressive symptoms and smartphone overdependence. Korean Journal of Play Therapy, 21(3), 343-363. doi:10.17641/KAPT.21.3.3

Jang, S.-H., Kim, S.-J., Choi, S.-Y., \& Lee, J.-Y. (2013). The effect of self-esteem, school adjustment, mental health on elementary school students' cellular phone addiction. The Journal of Child Education, 22(4), 243-256.

Jeong, J. S., \& Lee, H. K. (2020). A study on factors affecting smartphone addiction in children and adolescents: Focusing on the comparison between 4th-grade elementary school students and 1st-grade middle school students. Journal of Youth Welfare, 22(4). 211-241. doi:10.19034/ KAYW.2020.22.4.08

Jin, M. R., \& Shin, S. (2016). The effects of attachment trauma, self-esteem, depression, self-regulation on smart phone addiction in Korean adolescents: Focusing on 'Escape Theory Model'. Korean Journal of Addiction Psychology, 1(1), 31-53.

Kim, D., Kwon, M., Jeong, Y., Lee, Y., Jeon, H., Kim, B.,...Ko, Y. (2011). Restructing the smart media addiction proneness scale (Report No. NIA V-RER-14029). Seoul: National Information Society Agency.

Korea Information Society Development Institute. (2017). 2017 hangugmidi-eo paeneoljosa [2017 한국미디어 패널조사] (Report No. 2017-11-12). Retrieved from Korea Information Society Development website: https://stat.kisdi.re.kr/kor/ board/BoardList.html?board_class=BOARD33

Korea Information Society Development Institute. (2018). 2018 hangugmidi-eo paeneoljosa [2018 한국미디어 패널조사] (Report No. 2018-10-02). Retrieved from Korea Information Society Development website: https://stat.kisdi.re.kr/kor/ board/BoardList.html?board_class=BOARD33

Kwon, M., Nam, K., \& Seo, B. (2014). 2014 a survey on internet addiction (Report No. NIA V-RER-14112). Retrieved from http://library.nia.or.kr/search/detail/CATTOT 000000026318

Lee, E. J. (2019). Comparison of factors related to smartphone dependency among middle school, high school, and college students based on the seventh Korean children and youth panel survey. Child Health Nursing Research, 25(2), 165174. doi:10.4094/chnr.2019.25.2.165

Lee, H. J. (2017). Mediating effect of negative automatic thinking on the relationship between academic stress and depression among middle school students. Journal of Learner-
Centered Curriculum and Instruction, 17(13), 295-314. doi:10.22251/jlcci.2017.17.13.295

Lee, H. Y., \& Lee, Y. S. (2019). A Short term longitudinal study: Mediating effects of environmental factors in the relationship between excessive smartphone dependence and self-efficacy among middle school students. Korea Youth Research Association, 26(6). 193-219. doi:10.21509/ KJYS.2019.06.26.6.193

Lee, H., \& Yang, S.-M. (2018). Differential effects of parenting styles, psychological traits, and purpose of smartphone use upon Korean adolescents' smartphone dependence. Korean Journal of Journalism \& Communication Studies, 62(5), 175214. doi:10.20879/kjjcs.2018.62.5.006

Lee, M. R., \& Park, S. J. (2020). The structural relationship among parents' compulsory, autonomy support, smartphone overdependence and problem behaviors by school level. Korean Journal of Youth Studies, 27(5), 169-191. doi:10.21509/KJYS.2020.05.27.5.169

Ministry of Gender Equality and Family. (2015). 2015nyeon gajogsiltaejosa bunseog-yeongu [2015년 가족실태조사 분석 연구](Report No. 2015-65). Retrieved from Ministry of Gender Equality and Family website: http://www.mogef. go.kr/mp/pcd/mp_pcd_s001d.do;jsessionid=1ZH6ReIKvA hnycKKn94RdCai.mogef20? $\mathrm{mid}=$ plc503\&bbtSn=1

Ministry of Science and ICT., \& National Information Society Agency. (2019). 2018 seumateupon gwa-uijon siltaejosa [2018 스마트 폰 과의존 실태조사](Report No. NIA VI-RSE-C-18060). Retrieved from Internet Addiction Prevention Center website: https://www.iapc.or.kr/mediaView.do?idx=28\&article_ id=ICCART_0000000112982\&type=A1

Na, Y. S. (2013). The effects of the parents' child-rearing attitude on the smartphone addiction of small children. Journal of Early Childhood Education \& Education Welfare, 17(3), 3153.

Park, J.-H., \& Cho, J. (2020). Impact of negative emotions on youth's immersion in adult media: The mediation effect of smartphone dependence. Korean Journal of Journalism \& Communication Studies, 64(4), 86-131. doi:10.20879/kjjcs. 2020.64.4.003

Park, K. H., \& Park, E. M. (2014). The mediating effects of depression and aggression on the relationship between perceived parental rearing attitudes and smartphone addiction: A focus on gender differences. Korean Journal of Play Therapy, 17(2), 209-224.

Park, J. H. (2019). Recognition of smartphone dependence of adolescents at risk of smartphone addiction. Journal of The Korean Data Analysis Society, 21(4), 2095-2105. doi:10.37727/jkdas.2019.21.4.2095

Shin, H., \& Jeong, S.-H.(2018). The predictors of children and adolescents' smartphone addiction. Journal of Cybercommunication Academic Society, 35(3), 5-50. 


\section{doi:10.36494/JCAS.2018.09.35.3.5}

Song, Y., Oh, S., Kim, E., Na, E., Jung, H., \& Park, S. (2009). Damaeche hwangyeong-eseo cheongsonyeon-ui midi-eo hwal-yong bangsig-e daehan FGI yeongu: Seongbyeolgwa hwangyeongjeog yo-in-e ttaleun cha-ileul jungsim-eulo [다매체 환경에서 청소년의 미디어 활용 방식에 대 한 FGI 연구: 성별과 환경적 요인에 따른 차이를 중심 으로]. Journal of Communication Research, 46(2), 33-65. doi:10.22174/jcr.2009.46.2.33

Yang, J.-W., Hong, S., Jung, Y. S., \& Kim, J.-H. (2005). The validation study of Automatic Thoughts Questionnaire (ATQ-N) and the positive Automatic Thoughts Questionnaire (ATQ-P) in adolescents. The Korean Jounral of Clinical Psychology, 24(3), 631-646.

Yoo, G., Kim, S. H., Lim, J. H., \& Choi, H. R. (2011). Effects of the frequencies of family leisure and meals and family closeness on elementary school children's sociality. Journal of Family Resource Management and Policy Review, 15(3), 99-116.

Yoon, Y., \& Kim, J. (2019). The longitudinal relationship between depression and smartphone dependency in adolescents: Autoregressive cross-lagged modeling. Journal of School Social Work, 48, 219-241. doi:10.20993/jSSW.48.9
Yuh, J. (2015). The effects of family relations and parent-adolescent communication on adolescents' smartphone addiction symptoms: Examining the mediating role of self-esteem and impulsivity. Journal of Parent Education, 7(1), 101-112.

Yuh, J. (2016). The relationship between loneliness and smartphone addiction symptoms among middle school students: Testing the mediating role of self-esteem. Korean Journal of Youth Studies, 23(1), 129-152.

$\begin{array}{ll}\text { Daeun Kim } & \text { http://orcid.org/0000-0001-9095-6863 } \\ \text { Kyung Eun Jahng } & \text { http://orcid.org/0000-0002-7251-7864 }\end{array}$

Received June 29, 2021

Revision received August 20, 2021

Accepted October 4, 2021 